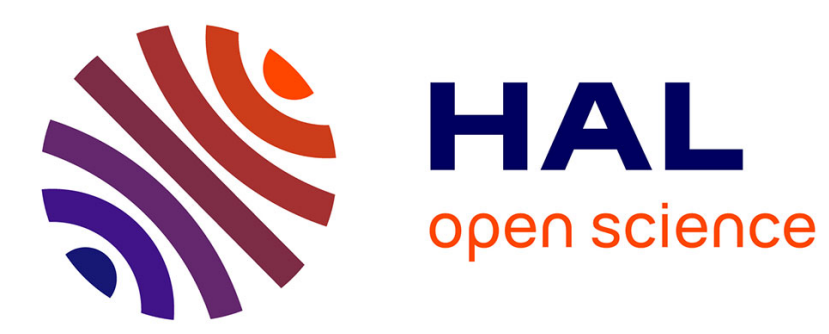

\title{
Critical Appropriations of Biosensors in Artistic Practice
}

Teoma Jackson Naccarato, John Maccallum

\section{To cite this version:}

Teoma Jackson Naccarato, John Maccallum. Critical Appropriations of Biosensors in Artistic Practice. MOCO 2017 - 4th International conference on movement and computing, Jun 2017, London, United Kingdom. 10.1145/3077981.3078053 . hal-01614245

\section{HAL Id: hal-01614245 \\ https://hal.inria.fr/hal-01614245}

Submitted on 10 Oct 2017

HAL is a multi-disciplinary open access archive for the deposit and dissemination of scientific research documents, whether they are published or not. The documents may come from teaching and research institutions in France or abroad, or from public or private research centers.
L'archive ouverte pluridisciplinaire HAL, est destinée au dépôt et à la diffusion de documents scientifiques de niveau recherche, publiés ou non, émanant des établissements d'enseignement et de recherche français ou étrangers, des laboratoires publics ou privés. 


\section{Critical Appropriations of Biosensors in Artistic Practice}

\author{
Teoma J. Naccarato \\ Center for Dance Research (C-DaRE) \\ Coventry University \\ Priory Street \\ Coventry, UK CV1 5FB \\ naccarat@coventry.ac.uk
}

\author{
John MacCallum \\ Inria, CNRS, Université Paris-Sud \\ Université Paris-Saclay \\ F-91405 \\ Orsay, France \\ john.maccallum@inria.fr
}

\begin{abstract}
In this article we discuss the ethical and æsthetic implications of the appropriation of biomedical sensors in artistic practice. The concept of cross-disciplinary appropriation is elaborated with reference to Guattari's ethico-æsthetic paradigms, and Barad's metaphor of diffraction as methodology. In reviewing existing artistic projects with biosensors, we consider ways in which the recontextualization of technologies, and likewise techniques, can both propagate and violate disciplinary expectations and approaches. We propose that by way of critical appropriations of biosensors in artistic practice-that is to say, de- and re-contextualizations of biosensors that acknowledge the shift of ecology and epistemology-artists have a vital role to play in troubling reductive representations of bodies, and furthermore, destabilizing the ethico-æsthetic boundaries of differently constituted disciplines.
\end{abstract}

\section{CCS CONCEPTS}

-Human-centered computing $\rightarrow$ Interaction design theory, concepts and paradigms; Collaborative and social computing theory, concepts and paradigms;

\section{KEYWORDS}

Critical appropriation, ethico-æsthetics, diffraction, biosensors, interaction design, contemporary dance, contemporary music

ACM Reference format:

Teoma J. Naccarato and John MacCallum. 2017. Critical Appropriations of Biosensors in Artistic Practice. In Proceedings of MOCO '17, London, United Kingdom, 28-30 fune 2017, 7 pages.

DOI: $10.1145 / 3077981.3078053$

\section{INTRODUCTION: APPROPRIATION ACROSS DISCIPLINES}

Look hard enough at any discipline and you will likely find technologies being used beyond their intended purpose. In the case of artistic practices incorporating new technologies, appropriation from other disciplines is not only common, but is the norm. When a technology moves from one discipline to another, it carries with

Permission to make digital or hard copies of all or part of this work for personal or classroom use is granted without fee provided that copies are not made or distributed for profit or commercial advantage and that copies bear this notice and the full citation on the first page. Copyrights for components of this work owned by others than the author(s) must be honored. Abstracting with credit is permitted. To copy otherwise, or republish, to post on servers or to redistribute to lists, requires prior specific permission and/or a fee. Request permissions from permissions@acm.org.

MOCO '17, London, United Kingdom

(c) 2017 Copyright held by the owner/author(s). Publication rights licensed to ACM 978-1-4503-5209-3/17/06 ..\$15.00

DOI: $10.1145 / 3077981.3078053$ it traces of the context, ethics and æsthetics of its original intended use, which in turn shape the context of its use in the foreign environment. In this new context, users are free to interact with it in ways that may violate the ethics of its use in its native discipline. Further, prolonged use engenders new ethical and æsthetic considerations, as well as pedagogies and notions of mastery, all of which may be in contradiction to those of its original discipline. This judgement of violation and contradiction is a situated one, however, and can just as easily be made from the perspective of the appropriator of the technology, originary arguments notwithstanding. The discourse between disciplines that share a technology is necessarily shaped by the differences in approach to, and the value systems that underlie, its use. While perceived naïvety or ethical transgression can negatively impact cross-disciplinary dialogue, surprising, non-normative use can also inspire innovation that had been hindered by ethical restrictions. Further, certain technologies can serve as the point of collaboration between disciplines.

In Chaosmosis: an ethico-æsthetic paradigm, Félix Guattari states that the ethics of a discipline can hinder its progression and lead to its calcification. The introduction of æsthetic considerations in the form of artistic practice can aid in the exploration of the edges of the discipline that may lie in the shadows cast by ethical gray areas.

\begin{abstract}
The incessant clash of the movement of art against established boundaries (already there in the Renaissance, but above all in the modern era), its propensity to renew its materials of expression and ontological texture of the percepts and affects it promotes brings about if not a direct contamination of other domains then at the least a highlighting and a re-evaluation of the creative dimensions that traverse all of them. Patently, art does not have a monopoly on creation, but it takes its capacity to invent mutant coordinates to extremes: it engenders unprecedented, unforeseen and unthinkable qualities of being. [7, p. 106]
\end{abstract}

He goes on to note that his own field of psychoanalysis "has everything to gain from putting itself under the aegis of this new type of æsthetic processual paradigm" and that in so doing, it may "reacquire the creativity of its wild years at the turn of the century." His point about art's lack of a monopoly on creation is well takenindeed, the practice of doing art is not the same thing as artistic practice; artistic disciplines are no less in danger of stagnation due to ethical restriction than any other field-indeed, artistic practice has often been eliminated from artistic disciplines. 
Regarding movements across disciplinary boundaries, quantum physicist-philosopher Karen Barad builds on Donna Haraway's conception of diffraction as a research methodology for addressing difference, or more specifically, "how different differences get made", without synthesis of æsthetic and ethical perspectives [1, p. 30]. The metaphor of diffraction points to encounters between differently constructed value systems in cross-disciplinary collaboration, by

illuminating the indefinite nature of boundariesdisplaying shadows in "light" regions and bright spots in "dark" regions-the relationship of the cultural and the natural is a relation of "exteriority within." This is not a static relationality but a doing - the enactment of boundaries-that always entails constitutive exclusions and therefore requisite questions of accountability.[1, p. 135]

Diffraction, and likewise appropriation, are potential methods by which to observe and investigate-or even destabilize-the pervasive ethical and æsthetic edges of a discipline. In this very article, the encounter of philosophy and art could be interpreted as diffractive and appropriative, rather than explicative. Likewise, the integration of biosensors within our artistic practice incites tension regarding æsthetic perspectives in contemporary dance versus contemporary music, with regards to interaction design and human-computer interaction, as well as between art and medicine.

In some cases however, the appropriation of technology may negatively impact communication across disciplines, particularly when the concerns central to one discipline are treated as subordinate to those of the other. From the point of view of a medical professional trained in the normative use of a biosensor, artistic use can appear naïve, obfuscating issues of intent and redirecting the medical gaze from the body to the health of one's artistic practice. Conversely, the appropriation of artistic technologies as representational modes for medical or scientific data subjugates elements of the creative process and turns the objects of scientific inquiry into unwitting performers open to æsthetic critique.

While design for reuse, co-adaptation, and appropriation has been studied extensively in the field of Human-Computer Interaction $[4,12,21]$, many of the specialized devices used in the medical field are designed without those principles in mind, and in some cases with intentional opposition to them. Medical electrocardiograms (ECGs), for example, are well-suited to their diagnostic use and are geared towards presenting doctors and technicians with a representation of their measurements that indexes their training and simplifies their use in typical scenarios. Use outside those scenarios may require the design of a new form factor, different modes and interpretation of the measured data, and different locations of their representation. The quantified self (QS) movement, for example, has in recent years focused on stylish, low-profile wearable devices that present their interpreted measurements without need for a medical professional, typically on a smartphone or smartwatch. ${ }^{1}$ A relatively new field, the success of the QS movement is due at least in part to its ability to separate itself from any perceived stigma associated with poor health that earlier uses of wearable medical technology might indicate. Indeed, QS as a movement was

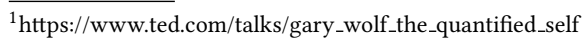

created by its own redesigns of appropriated technology as much as it was responsible for those same redesigns. Interestingly, many artists favor the use of popular, off-the-shelf biosensors designed for fitness training and self-tracking, rather than appropriating the relatively expensive and proprietary technologies employed by medical professionals.

In the case of our own appropriation of heart rate sensors for artistic research and creation, we found it necessary to design a wearable, wireless ECG for use during dynamic choreography, from which we register a sampled PQRST waveform [17]. A major benefit of designing our own unit is that we are free to alter the software to suit our needs as they evolve. Additionally, understanding aspects of the hardware and software design allows us to interpret ways in which the materiality of the ECG as instrument becomes part of the biosignal, as well as the performance context overall.

In the next section we narrow our discussion to the artistic appropriation of an iconic medical technology: the stethoscope, as an example of the ethical and æsthetic implications, as well as productive potentials, produced by cross-disciplinary transgressions.

\section{THE APPROPRIATED STETHOSCOPE: MEDIATION AND MATERIALITIES}

In Western medical practice the body is being examined in a particular light, in order to serve goals such as diagnosing an illness. When medical tools, such as biosensors, are appropriated for use in an artistic context, it is productive to consider the ways in which these technologies are employed, and with what intentions. How do we qualify the difference between when a doctor places a stethoscope to the chest of a patient, versus when an artist places a stethoscope on the chest of a performer? If the goal in an artistic practice is no longer to diagnose illness, then what alternate motives are at play?

In early Greek medicine dating back to Hippocrates of Cos (circa 460 BC - 377 BC), diagnosis was made primarily based on the patient's own account of symptoms, augmented by sensory techniques including visual inspection, palpation, percussion (tapping on the body to assess solid masses like organs versus air-containing structures, as well fluids in the chest or abdomen), and auscultation (listening to sounds inside the body, like the lubdub produced by the closing of the heart valves) [10, p. 10]. While these visual, tactile, and aural biosignals remain extremely useful in evaluation, it was recognized early on that they are highly subjective. In his work on biomedical signals and sensors, Eugenijus Kaniusas notes that "[a]nalysis of the biosignals was restricted to instantaneous impression by the physician, with the impression being strongly affected by the physician's personal experience" [10, p. 12]. Kaniusas details three attempts to objectively record, reproduce, compare, and share biosignals, developed chronologically, namely: "verbal descriptions, musical notation, and technical tools" [10, p. 12-13] In the case of musical notation, the height of the notes on the staff was used to express qualitative characteristics of the biosignal, while the lateral distribution of the notes indicated rhythm [10, p. 13]. One example is the work of flute teacher François Nicolas Marquet (1687-1759), who used musical notation to document thirty different behaviors of the pulse, as a way to evaluate changes in blood pressure [10, p. 13]. 
During the $19^{\text {th }}$ century the development of medical technologies such as the stethoscope and electrocardiogram played a significant role in human understandings of the heart, and began to address the aforementioned concerns of recording, reproducing, comparing, and sharing biosignals. The conception of the stethoscope is attributed to a critical moment in 1816, when the French doctor René Théophile-Hyacinthe Laennec had the ingenious idea to roll up a tube of paper against a patient's chest, through which he listened to the amplified sounds [20, p. 117]. Subsequent prototypes of the stethoscope, both analog and digital, continue to hone the filtering and amplification of audio frequencies through hardware and software, corresponding to heart, lung, and snoring ${ }^{2}$ sounds [10, p. 3].

The introduction of the stethoscope has been theorized as a form of mediation between doctor and patient, supplanting the technique of immediate auscultation, in which doctors placed an ear directly to the chest of a patient to listen [20, p. 118]. Sterne argues that:

\begin{abstract}
While empiricism is usually cited as the operative epistemology of early modern medicine, an epistemology of mediation is equally central to the apprehension of that sensory data which would yield up its truth: you had to have the right tools and training to hear it for yourself; the truth might not immediately yield itself up for the untrained listener. [20, p. 118]
\end{abstract}

Within this distinction between immediate and mediate sensing is the suggestion that there exists some form of independent "truth" that is being obscured (or mediated) by the approach of the human examiner, whose socially constructed perspective shapes perception and diagnosis. In Sterne's words: "for the sounds produced by mediate auscultation to signify properly-that is to say, indexicallyit demands a facility with technique, a certain level of virtuosity" [20, p. 134]. With regards to the involvement of the stethoscope in the act of perception, Sterne points out that historically:

As a part of the instrumental reasoning underlying the entire procedure, the character of the instrument itself must be erased from consciousness during mediate auscultation. In classic technological deterministic fashion, the tool stands in for a whole process from which it erases itself. [20, p. 123]

In the moment of holding a stethoscope to a person's chest, it may be difficult to forget the presence of the instrument itself. And yet, this call for erasure has resonances in how technologies are involved in medical, as well as artistic practices, to present day. For example, when we claim to be listening to the heart with a stethoscope, the erasure of the instrument from the process is already underway. The amplification facilitated by a stethoscope affects the quality of the sounds perceived, based in part on the material composition of the tool, and its placement on the body. In digital stethoscopes, there are built-in filters (similar to the bell and diaphragm in analog stethoscopes), which can be used to emphasize

\footnotetext{
${ }^{2}$ The "snoring sounds arise in the upper airways due to elastic oscillation of pharyngeal walls" [10, p. 3].
}

particular frequency ranges that correspond to the heart, lung, or snoring sounds, depending on the priorities of the listener. ${ }^{3}$

Importantly, the distinction in Sterne's article between immediate and mediate auscultation in medical history (i.e. the doctor listening with an ear to the patient's chest, versus with a stethoscope), assumes that there is such a thing as direct, unaffected listening. To the contrary, each human ear has its own folds and form that shift throughout life, thus filtering sounds differently. Additionally, sound perception is informed by one's quality of attention and interest in the task at hand [19]. As such, the role of the stethoscope becomes entangled within the listening process in ways that cannot be causally extricated from "immediate" (or pre-culturally constructed) sensing. This is not due to lack of skill, but rather, it is because un-mediated sensing does not exist. The erasure of the instrument from the perceptual process is important to consider, because it obscures the relationships and meaningmaking underway, by allowing the ethical and æsthetic values that inform its operation, in particular values rooted in biological and social determinism, to remain unexamined.

Critically, within this theorization of the stethoscope as perceptual mediator between the heart/body being listened to, and the human listener, there lies an implicit assumption: namely, that the "source" and "receiver" are separate and distinguishable entities to begin with, that come into contact at the point of mediation. This contact between doctor and patient, or likewise director and performer, is influenced by the value-laden design of the hardware and software, which necessarily involves amplification, averaging, and exclusion of aspects of the resultant biosignal. Moreover, as a mediating technology, it may be assumed that the stethoscope extends ${ }^{4}$ the capacities of the active listener (and their "trained ear") to penetrate the closed and passive heart/body under examination. The hope, it seems, is that by revealing the enunciations of the heart, the stethoscope will allow the investigator greater access to, and understanding of this evasive thing-we-call-the-heart. Invocations of technology as a mediating force to reveal the intimate interiors of bodies, and augment the sensory capacities of the investigator, arguably (and perhaps inadvertently) reinforce binaries of passive/active and object/subject. Once divided, this passive object and active subject can be made to interact through cause and effect, which involves unidirectional channels of influence. The implications of this paradigm of mediated interaction are profound and pervasive in their infiltration of cultural values and practices, in the arts and sciences alike.

In our own collaborative, artistic practice, we came to investigate the appropriation of digital stethoscopes and transducers through a performance-installation titled Synchronism [16], which consists of three simultaneous components:

(1) Individuals are invited, one at a time, to join the performer inside a private booth. With electronic stethoscopes and transducers the duo shares the rhythms of their hearts in real-time, stimulating sites of pulsation on their own and one another's bodies. Issues of mutual trust, consent, and play are negotiated nonverbally, as the pair transgresses

\footnotetext{
${ }^{3}$ Example of filters in digital stethoscopes: http://www.thinklabs.com/filtering.

${ }^{4}$ The concept of technology as an extension of the human body was promoted by media theorist Marshall McLuhan [15], and has had profound resonances in the visual and performing arts alike.
} 
boundaries of internal versus external, and self, other, and environment.

(2) Bodies mix and spread further as the cardiac, respiratory, and fluid sounds of each person are used to enliven a multichannel, spatialized audio installation throughout the surrounding area for everyone present. Live sounds from the two stethoscopes are processed to immerse the audience in the noisy æsthetic of closely amplified skin, hair, and clothes of current and past encounters.

(3) In addition, there is a large scale, labyrinth-like paper sculpture dominating the public space. Several transducers attached to the paper cause it to pulse as audio flows from the stethoscopes throughout its surfaces. The public is encouraged to touch, embrace, and be enveloped by the architectural folds of the sculpture, as it evolves in concert with the intimate performance and sonic scape.

Through the above proposals, bodily rhythms from participants are (re)collected, (re)materialized, and (re)distributed, such that perceived boundaries of self, other, and environment become ambiguous. Ephemeral acts and interactions take form only to diffract as patterns in the sonic, visual, and haptic dimensions of the installation. In Synchronism, the stethoscope is not only positioned as a mediator between performers, but rather, as a mediating element within the range of materializations that become the event. The stethoscope acts as an intervention in our imagining of the relationships between performers, participants, and multimedia, in a manner that is differentiated from diagnostic specificity or objectivity in medical practice. Rather than engaging with clinical assessment (which of course serves an important purpose elsewhere), we appropriate the stethoscope as an intervention in our ethico-æsthetic techniques for listening through touch, to bodiesas-processes. Our intention as artists is that, through the de- and re-contextualization of the stethoscope into an artistic context, the epistemic regimes and ethico-aesthetic paradigms of the disciplines in which the stethoscope finds itself will come into a diffractive relation.

Importantly, our work follows in the footsteps of many performance artists and philosophers who challenge deterministic conceptions of bodies, and investigate the liminal spaces between disciplines. Since the mid-late $20^{\text {th }}$ century, performance artists such as Marina Abramovic, Eduardo Kac, Orlan, VNS Matrix and Stelarc have appropriated biotechnologies as a means to critique the concept of the body as a stable, self-contained entity that can be quantified and represented by other means. Likewise, feminist philosophers such as Kuppers [11], Butler [3], Grosz [5, 6] and Manning $[13,14]$ discuss the body "as a process, which is unbound by the skin" [17, p. 61]. Haraway [8], Hayles [9], and Bradiotti [2] "theorize performative renderings of cyborg and posthuman bodies that blur boundaries between human/machine and biological/computational" [17, p. 61].

In the coming section, we reflect on the appropriation of biosensors in contemporary music and dance since the 1960s, with attention to the ethical and æsthetic dimensions of such de- and recontextualizations of technologies. Importantly, we could likewise discuss the (re)appropriation of artistic practices with biosensors into medical settings, for example in projects that invite artists into hospitals-but this is beyond the scope of the current article. From medicine to art or art to medicine, our argument remains: in every transgression across disciplinary boundaries, the ethical and æsthetic negotiation between collaborators, implicit or explicit, lays the foundation from which research and creation is performed.

\section{BIOSENSORS IN ARTISTIC PRACTICE: ETHICO-ÆSTHETIC TRENDS}

In our article "From representation to relationality: Bodies, biosensors and mediated environments" we argue that the integration of biosensors in artistic practice over the past century has progressed hand in hand with shifting socio-political attitudes towards the body, related to biological and social determinism [17, p. 57]. We outline that since the 1960s the integration of biosensors in contemporary music and dance has been characterized by what Ortiz et al. [18, p. 12] label "biocontrol", as evidenced in early biosignal-driven music by composers such as Alvin Lucier, Richard Teitelbaum and David Rosenboom, as well as more contemporary researchers such as Benjamin Knapp, Marco Donnarumma and Atau Tanaka [17, pp.58-59]. Biosensors have likewise been, and continue to be, integrated in many contemporary dance projects by choreographers such as Wayne McGregor, Isabelle Van Grimde, Robert Wechsler, Anne Holst and Jean-Marc Matos, Jess Curtis, and Louise Wagner. As elaborated in our previous article, biocontrol involves using sensors to measure aspects of physiology, such as the electrical activity of the heart or brain, and "mapping" this biodata in a causal relation to parameters of computational media, e.g. using ECG data from a dancer to control light or sound levels during a performance. Through interaction design, mappings between bodies and computational media may be multi-layered and involve randomization, or even evolve algorithmically over the course of an event by way of machine learning [17, p. 59].

However, even in the most obvious instances of cause and effect between body and media, the directness of this mapping is an illusion. The process of deriving biodata from the body via sensors and using this data to inform aspects of other media is complex, and is shaped by the hardware, software, designers and context of the performance. When we hear a drumbeat that is meant to represent the beating of the human heart (i.e. mapping a heartbeat to a drumbeat), we are not merely learning about the heart rate of the performer. Rather, the designers have made a series of choices, including: which peak of the ECG to sonify; the sampling rate of data from the ECG monitor; the placement of electrodes on the body of the performer; and the quality and volume of the drumbeat-to list but a few of the mediating elements that impact perceptions of a one-to-one mapping. While creating the illusion of control between body and media is a popular strategy, and one that, in our experience, yields a certain satisfaction from performers and observers alike, we are concerned that relying heavily on 
this approach propagates a reductionist and binary understanding of the dynamics at play between bodies and media. [17, p. 59]

Furthermore, examining the concept of biosignal "noise" or "interference" hints at the ethical implications of causal and controlbased mappings in interaction design. In a stream of recorded biodata, "noise" is considered any data that is extraneous to the behavior that the designers or artists care to study. This noise may be due to any number of factors in the hardware or software, e.g. a broken lead cable on an ECG, or jitter in the Wi-Fi network, or it may be an unanticipated aspect of physiology, like a cardiac arrhythmia. When biosensors are used in contemporary dance, in which choreography may involve dynamic and unpredictable bodily movements, the biosignal can become very noisy. As a result, it may be difficult to map biodata to other media in predictable ways, making it near impossible to reproduce an æsthetic vision from one performance to the next. In artistic projects involving sensor data, it is common for the designers to filter out noise, and also to normalize data, by scaling it within a common value range, e.g. from 0 to 1 , for all bodies, in all situations. Once sensor data has been filtered and normalized, it can be used to control parameters of other media, such as the intensity of the lights or the volume of the music, in a more predictable and reproducible manner.

Arguably, noise reduction and normalization of data leads to an erasure of context, as well as normalized interpretations and representations of bodies. When we remove all divergent behavior from a biosignal, because it does not fit our expectations of how the body usually acts, or should perform, we delimit our capacity to observe bodily differences.

We will give an example of the ethical slipperiness of this approach using motion-tracking, and then we will return to a case study involving ECG data. A few years ago we observed a choreographer working with a motion-tracking system that he was marketing specially for people with disabilities. In this system, the participant moves in front of the camera, and sounds are generated in real-time based on pre-selected mappings (e.g. faster movements cause louder sounds). In this moment, the participant (we will call him Tom) was a man with Parkinson's, who also happened to be a composer. As Tom improvised with the particular movement patterns and qualities available in his body, the software had trouble tracking his gestures, and as such, kept loosing him. The choreographer repeatedly asked Tom to "just stand still," so that the tracking system could calibrate his skeleton. It was not possible for Tom to "just stand still." Jokingly, but perhaps also with a hint of frustration, the choreographer said to Tom "you broke my system." Because Tom's particular movements did not conform to the expectations of the software (as preset by the human designers), his body was literally invisible to the tracking system. Despite the choreographer's desire to market his motion-tracking system for people with disabilities, he created a program that was very limited in its capacity to process-nevermind embrace-bodily differences. It was apparent, and not surprising, that the reference point of the system was situated in the body of the choreographer who seemed to view the non-normative movements of otherly-abled individuals as problematic. Importantly, the choreographer and software designers could not have created a system based on preset mappings of cause and effect between movement and media that was available to all bodily configurations and capabilities. In collaborations that involve movement and computing, the movement of the performer does not only point inward to the body as a self-contained entity; rather, movement hints at relationships between the body of the human performer with other elements in the given context, including the hardware and software being used for computation, as well as the designers of the interactive system. Software and hardware systems necessarily reflect and propagate the ethical and æsthetic value systems of their designers, whether intentionally or not.

As a further case study, this time involving biosensors, we turn to the "Heart Chamber Orchestra" (HCO), a project by Terminalbeach artists Peter Votava and Erich Berger. ${ }^{5}$ In this production, each of the twelve musicians wears an electrocardiogram (ECG) from which heart rate data is registered and processed in the computer software. The twelve data streams are compared to generate a "group pulse," as well as interpretations of relationships between the individual pulses. Based on an algorithmic analysis of the ECG data, the musical score is adapted, and a few seconds later, appears on each musician's dedicated computer monitor, to be played live. The instrumentation is accompanied by electronic music and projected visuals, which are likewise reactive to the processed heart rate data.

In looking at a video of HCO from 2010 on the project blog, ${ }^{6}$ as well as an article co-authored by Votava and Berger in 2012, it is apparent that the artists have devised an extremely complex network of possible interactions, or flows of relation, between human performers with one another, as well as with aspects of the musical and visual landscape [22]. The task they are asking of the orchestra, i.e. to follow a notational score live while playing together within the unpredictable unfolding of each performance, along with live electronics, visuals, and moreover the presence of an audience, demands a particularly challenging, multi-directional spreading of awareness. In our opinion this distributed awareness is an aspect of all performance scenarios, but the conditions developed in HCO have potential to further a mode of performative attention that is not directed towards individual bodies or experiences alone, but rather, towards the relationships between animate and inanimate performers, within an emergent context.

In Votava and Berger's description of the relationships between biosignals and media, they emphasize not just the revealing of the heartbeats of the performers, but instead, the sharing of interpretations of heartbeats through the software program [22]. This is an important distinction, because it undercuts claims of direct access and mapping between physiological processes (as input) and media (as output). It is contradictory then, their subsequent insistence on ensuring legible representations of pulse through the music and lighting. They assert that:

Musically motivated mapping generates a narrative from arbitrary processes. In order to be successful, it needs to create "meaningfulness", which happens when the listener feels or clearly perceives certain aspects of the source processes in the music. To make the musical

\footnotetext{
${ }^{5}$ The HCO premiered in 2006 in Norway, and was presented several more times up until 2012 in the Netherlands, Austria, Finland, Brazil, Spain, France, and the USA, winning three different awards.

${ }^{6} \mathrm{HCO}$ project blog: http://heartchamberorchestra.org/wordpress
} 
results of compositional mapping credible, qualities that are considered to be characteristic for 12 heartbeats need to be sufficiently apparent in elements of the music. [22]

They identify the characteristic qualities between multiple heart rate signals to include asynchrony, percussiveness, and variability, and advise not to use "obvious harmonic melodies, except where the distortion of harmony is applied for creating meaningfulness" [22]. These claims by Votava and Berger assume: 1 . that by producing a legible representation of heart activity (legible to whom?), they gain credibility (with whom?) and; 2. that they have control over the meaning-making process of a performance, by which "arbitrary processes" come to signify (for whom?). "Musically motivated mapping" is a highly subjective criterion, and moreover, we disagree that the processes on which any mapping draws are "arbitrary" and only come to matter through human intervention.

Votava and Berger carry on, explaining that: "The intention here is to represent the musician's pulses. Although a bi-directional communication channel between musicians and the computer is created, no 'moderation' of their communication is applied, for it is led by the feedback loop itself" [22]. This statement suggests that the feedback loop between performer and computer is unaffected by the æsthetic design process, despite the layers of mapping between biosignals and media that the artists have employed. This is another example of how the techniques and technologies of interaction can become obscured or erased from the final performance, allowing the ethico-æsthetic value system at play to slink stealthily backstage. Furthermore, this account does not interrogate the role of past training in how each performer engages within the performance context. Akin to Sterne's "trained ear", the musicians necessarily have a complex sociocultural situatedness, which cannot be understood as deterministic of their relational capacities, but is arguably entangled with how they perceive and act in a shared environment.

Votava and Berger's use of biosensors to capture the behaviour of each musician's heart assumes an empirical conception of what the heart is (as quantified with biosensors), and therefore of what the heart can do (as represented musically and visually). While the interaction design in $\mathrm{HCO}$ ranges from direct mappings to algorithmic exchanges, a narrative of casualty and representation between bodies and media persists. In control-based interaction, be it with biosensors or motion tracking, comparable assumptions regarding what bodies (or body parts, or bodily processes, or bodily gestures) are, and therefore can do, form the ethical basis from which aesthetic mappings are designed.

Arguably, biocontrol as an artistic method not only adopts the tools of biomedical research, but also reproduces the value system that operates within medical practice, including beliefs about what a body is. In scenarios of appropriation, such as in HCO or in our own work, the question is not whether the encountered value systems are good or bad or right or wrong, but rather, what goals these values propagate in a given (disciplinarily-constructed) context. Attempts to transpose tools and methods from one discipline to another (i.e. from medicine to art), fail to take into account the ethical character of practices, which are never neutral. Critically, when appropriating the technologies of a specific disciplinary culture, artists have an opportunity to investigate the ethical and aesthetic functioning of such technologies-not only to deconstruct the values at work-but also to produce diverse and divergent practices of engagement across disciplinary boundaries.

\section{CONCLUSION}

Collaborative work across disciplines is continually shaped by the appropriation of technologies endemic to each discipline. When these technologies transit across borders and are used in unfamiliar or unexpected ways, the discourse of the collaboration runs the risk of death by a thousand cuts as minuscule violations of the ethics of their use compound. Conversely, when cross-disciplinary appropriation and collaboration are considered diffractively, that is, with attention to how the ethico-æsthetic boundaries of each discipline are enacted, non-normative uses of technology can shed light in the "dark' regions" of each field, and disturb the shadowy edges of disciplines that lie in ethical grey areas [7, p. 135].

We contend that critical appropriation is necessary in order to prevent subjugation, and enable collaboration across disciplines. Critical appropriation involves the process of intentionally and explicitly deconstructing the ontology of technologies in order to rebuild them with and through a value system shared by all participants in the collaboration. In surveying the use of biosensors in contemporary dance and music since the 1960s, we propose that the dominance of control-based mappings between bodies and media, i.e. biocontrol, is an example of artists appropriating not only the tools of biomedicine, but also (and inevitably), the values of medical practice with regards to measuring and representing what bodies are, and therefore what bodies can do.

In this transposition of technology across disciplinary lines, the rigour and scepticism of diagnostic practice may be diminished, because artists have different disciplinary training, and divergent (non-medical) goals. Likewise, the rigour of choreographic and compositional practices may be undermined by the imitation of foreign techniques for research, which serve the intentions of an alternate discipline. Fortunately, disciplinary subordination is not inevitable in cases of appropriation and collaboration. Provided that each collaborator can acknowledge and share the specificity of their disciplinary training and values, multiple, differently constituted perspectives can move in, through, and around one another without synthesis or consensus. Through the meeting of multiple disciplines-in our case contemporary dance, music, performance art, human-computer interaction, biomedicine and philosophydivergent perspectives become entangled to produce provocations, and potential for diffractive collaboration.

\section{ACKNOWLEDGEMENTS}

This work was supported in part by ERC project CREATIV (ERC2012-ADG_20120216).

\section{REFERENCES}

[1] Karen Barad. 2007. Meeting the Universe Halfway: Quantum Physics and the Entanglement of Matter and Meaning. Duke University Press, London.

[2] Rosi Bradiotti. 2013. The Posthuman. Polity Press, Cambridge.

[3] Judith Butler. 2008. Gender Trouble: Feminism and the Subversion of Identity. Routledge, New York.

[4] Alan Dix. 2007. Designing for Appropriation. In Proceedings of the 21st BCS HCI Group Conference. British Computer Society, Lancaster University, UK, 210-217. 
[5] Elizabeth Grosz. 1994. Volatile Bodies: Toward a Corporeal Feminism. Allen \& Unwin, Sydney.

[6] Elizabeth Grosz. 2011. Becoming Undone: Darwinian Reflections on Life, Politics, and Art. Duke University Press, Durham.

[7] Félix Guattari. 2002. Chaosmosis: an ethico-æsthetic paradigm. Indiana University Press, Bloomington. Trans. Bains, P. and Perfanis, J.

[8] Donna Haraway. 1991. A Cyborg Manifesto: Science, Technology, and socialistfeminism in the late twentieth century. In Simians, Cyborgs and Women: The Reinvention of Nature. Routledge, New York, 149-181.

[9] N. Katherine Hayles. 2008. How We Became Posthuman: Virtual Bodies in Cybernetics, Literature, and Informatics. University of Chicago Press, Chicago.

[10] Eugenijus Kaniusas. 2012. Biomedical Signals and Sensors 1: Linking Physiological Phenomena and Biosignals. Springer, New York.

[11] Petra Kuppers. 2007. The Scar of Visibility: Medical Performances and Contemporary Art. University of Minnesota Press, Minneapolis.

[12] Wendy Mackay. 2000. Responding to Cognitive Overload: Co-adaptation Between Users and Technology. Intellectica 30, 1 (2000), 177-193.

[13] Erin Manning. 2009. Relationscapes. MIT Press, Cambridge.

[14] Erin Manning. 2013. Always More Than One: Individuation's Dance. Duke University Press, Durham.

[15] Marshall McLuhan. 1964. Understanding Media: Extensions of Man. McGraw-Hill, New York.

[16] Teoma J. Naccarato and John MacCallum. 2012. Synchronism. (2012) https://ccinternaltime.wordpress.com/residencies/ircam/performancestudies/synchronism/.

[17] Teoma J. Naccarato and John MacCallum. 2016. From Representation to Reality: Bodies, Biosensors and Mediated Environments. Fournal of Dance and Somatic Practices 8, 1 (2016), 55-70.

[18] Miguel Ortiz, Niall Coghlan, Javier Jaimovich, and Benjamin Knapp. 2011 Biosignal-Driven Art: Beyond Biofeedback. Ideas Sonicas/Sonic Ideas 3, 2 (2011) 43-52.

[19] Joel S. Snyder, Melissa K. Gregg, David M. Weintraub, and Claude Alain. 2012 Attention, Awareness, and the Perception of Auditory Scenes. Frontiers in Psychology 3, 15 (2012). Human-Computer Interaction.

[20] Jonathan Sterne. 2001. Mediate Auscultation, the Stethoscope and the "Autopsy of the Living": Medicine's Acoustic Culture. Journal of Medical Humanities 22, 2 (2001), 115-136.

[21] Pierre Tchounikine. 2016. Designing for Appropriation: A Theoretical Account. Human-Computer Interaction (2016), 1-41.

[22] Peter Votava and Erich Berger. 2012. The Heart Chamber Orchestra. (2012). http://heartchamberorchestra.org/wordpress. 